\title{
Airglow-imaging observation of plasma bubble disappearance at geomagnetically conjugate points
}

\author{
Kazuo Shiokawa ${ }^{1 *}$, Yuichi Otsuka ${ }^{1}$, Kenneth JW Lynn², Philip Wilkinson ${ }^{3}$ and Takuya Tsugawa ${ }^{4}$
}

\begin{abstract}
We report the first observation of the disappearance of a plasma bubble over geomagnetically conjugate points. It was observed by airglow imagers at Darwin, Australia (magnetic latitude: $-22^{\circ} \mathrm{N}$ ) and Sata, Japan $\left(21^{\circ} \mathrm{N}\right)$ on 8 August 2002. The plasma bubble was observed in 630-nm airglow images from 1530 (0030 LT) to 1800 UT (0300 LT) and disappeared equatorward at 1800 to 1900 UT (0300 to 0400 LT) in the field of view. The ionograms at Darwin and Yamagawa (20 km north of Sata) show strong spread-F signatures at approximately 16 to 21 UT. At Darwin, the F-layer virtual height suddenly increased from approximately 200 to approximately $260 \mathrm{~km}$ at the time of bubble disappearance. However, a similar F-layer height increase was not observed over the conjugate point at Yamagawa, indicating that this F-layer rise was caused not by an eastward electric field but by enhancement of the equatorward thermospheric wind over Darwin. We think that this enhancement of the equatorward neutral wind was caused by an equatorward-propagating large-scale traveling ionospheric disturbance, which was identified in the north-south keogram of 630-nm airglow images. We speculate that polarization electric field associated with this equatorward neutral wind drive plasma drift across the magnetic field line to cause the observed bubble disappearance.
\end{abstract}

Keywords: Plasma bubble disappearance; Conjugate observation; Airglow imaging

\section{Background}

An equatorial plasma bubble is a spectacular structure in the equatorial F-region ionosphere caused by the ionospheric Rayleigh-Taylor instability (e.g., Woodman and La Hoz, 1976; Kelley, 1989). It causes significant scintillation of radio signals from satellites due to plasma irregularities (e.g., Basu et al. 1996; Uma et al. 2012; Park et al. 2013). Thus, the study of plasma bubble characteristics is important for maintaining stable communication between the satellites and the ground.

Recent airglow imaging using highly sensitive cooledcharge coupled device (CCD) cameras has shown detailed structures and dynamics of the plasma bubbles through airglow emissions at wavelengths of 630.0 and $777.4 \mathrm{~nm}$, which have emission layers at the bottom of the $F$ layer and near the F-layer peak, respectively (e.g., Mendillo and

\footnotetext{
*Correspondence: shiokawa@stelab.nagoya-u.ac.jp

1 Solar-Terrestrial Environment Laboratory, Nagoya University, Furo-cho,

Chikusa-ku, 464-8601 Nagoya, Japan

Full list of author information is available at the end of the article
}

Baumgardner, 1982; Rohrbaugh et al. 1989; Tinsley et al. 1997; Aarons et al. 1999; Sahai et al. 2000; Makela and Kelley, 2003). Makela et al. (2006) showed the development of a secondary instability at the eastern wall of the plasma bubbles by using an airglow imager in Hawaii. Conjugacy of plasma bubbles along the geomagnetic field line has been confirmed using airglow imagers operated simultaneously in the northern and southern hemispheres (Otsuka et al. 2002; Ogawa et al. 2005; Martinis and Mendillo, 2007; Abdu et al. 2009). Shiokawa et al. (2004) showed that the conjugacy is maintained even during the growth phase of the plasma bubbles toward higher latitudes.

Plasma bubbles are usually generated near the sunset terminator associated with the strong upward drift of the ionosphere due to evening enhancement (e.g., Fejer et al. 1999). In airglow images taken at night, the bubbles usually appear from the western edge of the images and drift eastward following the background eastward plasma drift. Sobral et al. (2011) reported a small fraction $(0.5 \%$ to $3.65 \%$ ) of bubble events that show midnight reversal of

\section{Springer}

(c) 2015 Shiokawa et al.: licensee Springer. This is an Open Access article distributed under the terms of the Creative Commons Attribution License (http://creativecommons.org/licenses/by/4.0), which permits unrestricted use, distribution, and reproduction in any medium, provided the original work is properly credited. 
the eastward motion to westward during geomagnetically quiet times. We do not know of any reports that show the disappearance of plasma bubbles in the field of view of airglow images. This lack is probably because plasma diffusion across the magnetic field lines is too slow to dissipate the bubble structure at night. As the result, plasma bubbles created at the sunset terminator can survive for a long time and keep drifting zonally until sunrise. Otsuka et al. (2012) recently made an interesting observation, over Shigaraki, Japan, of plasma bubble disappearance due to the interaction with medium-scale traveling ionospheric disturbances (MSTIDs). The disappearance of the bubble was likely to be caused by plasma drift across the geomagnetic field line following the polarization electric field in the MSTIDs.

In this paper, we report a plasma bubble disappearance in the field of view of the 630-nm airglow images observed simultaneously at geomagnetically conjugate points. The disappearance was not associated with MSTIDs. A sudden F-layer height increase was observed in the southern hemisphere at the time of the bubble disappearance. We suggest that the disappearance of the plasma bubble was caused by the polarization electric field associated with a large-scale traveling ionospheric disturbance.

\section{Methods}

We use airglow images obtained at the nearly geomagnetically conjugate points of Sata, Japan $\left(31.0^{\circ} \mathrm{N}, 130.7^{\circ} \mathrm{E}\right.$; geomagnetic latitude: $21^{\circ} \mathrm{N}$, dip angle: $\left.44^{\circ}\right)$ and Darwin, Australia $\left(12.4^{\circ} \mathrm{S}, 131.0^{\circ} \mathrm{E}\right.$; geomagnetic latitude: $22^{\circ} \mathrm{S}$, dip angle: $-40^{\circ}$ ). As described by Shiokawa et al. (2004), the two all-sky airglow imagers (imager 2 at Sata and imager 4 at Darwin) were developed in the Solar-Terrestrial Environment Laboratory, Nagoya University, as part of the Optical Mesosphere Thermosphere Imagers (OMTIs). Airglow images at a wavelength of $630.0 \mathrm{~nm}$ (OI, emission altitudes: 200 to $300 \mathrm{~km}$ ) were obtained every 5.5 and 6 min at Sata and Darwin, respectively, with an exposure time of $165 \mathrm{~s}$. Airglow images at 777.4 nm (OI, emission altitudes: 300 to $400 \mathrm{~km}$ ) were also obtained every $30 \mathrm{~min}$ at Darwin with the same exposure time. Background continuum emission from the sky was monitored every 30 min at a wavelength of $572.5 \mathrm{~nm}$ to estimate the absolute intensity of these airglow lines. The imager at Sata, Japan, has been operated since July 2000. The imager at Darwin, Australia, has been operated since October 2001. Details of these imagers are given in Shiokawa et al. (1999; 2000; 2009). The geomagnetically conjugate point of Darwin is located $250 \mathrm{~km}$ southeast of Sata. Airglow images mapped from Darwin to the northern hemisphere along the geomagnetic field line mostly overlap the airglow images at Sata, since the field of view of an all-sky imager is about $1,000 \mathrm{~km}$ in diameter. The local time of these stations is approximately $9 \mathrm{~h}$ ahead of UT.
Additional file 1 is a movie of the all-sky 630-nm airglow images obtained at Darwin from 1002 UT (1902 LT) to 2020 UT (0520 LT) on 8 August 2002. The top of the image is north and to the left is east. The sky was fairly clear throughout this night. The plasma bubble structures, which are characterized as dark tree-like structures extending from the north (i.e., from the equator), started to appear at the western edge of the images at approximately 1530 UT. They moved eastward from 1530 to 1730 UT. Then, the eastward drift speed of the bubbles slowed down, and the structures started to vanish equatorward. All the bubble structures had disappeared from the images by 1930 UT.

Additional file 2 is a movie of the all-sky 630-nm airglow images obtained at Sata, Japan, from 1102 (2002 LT) to 1937 UT (0437 LT) on 8 August 2002 in the same format as that in Animation 1. The sky was hazy with some faint clouds passing occasionally. The plasma bubble structures, extending from the south (i.e., from the equator), appeared at the southwestern edge of the images at approximately 1530 UT. They moved eastward from 1530 to 1730 UT. Then, the structures tended to disappear equatorward after $1830 \mathrm{UT}$, although the sky became hazier which impeded observation. The bubble structures had disappeared in the images by 1930 UT.

Figure 1 shows several representative images of the bubble disappearance observed at Darwin (a to f) and Sata (g to l) on 8 August 2002. To see the bubble structures more clearly, we show the deviation of intensity $I_{d}=\left(I-I_{a}\right) / I_{a}$ in percent from 1 -h running averages $I_{a}$, where $I$ is the intensity (raw count) of the image. The timings of the images at Darwin and Sata are nearly the same. The bubbles appeared from the east at approximately $1530 \mathrm{UT}$ (0030 LT). Their structure started to become fainter from the images at approximately 1832 UT. The bubbles have almost vanished at approximately 1902 UT (0402 LT) in both northern and southern hemispheres. We note that even after this rather sudden disappearance of the bubbles, some faint structures remain recognizable until the end of the observation (2020 UT at Darwin and 1937 UT at Sata).

Figure 2 shows the east-west cross sections (keograms) of the 630-nm airglow images obtained at (a) Sata and (b) Darwin on 8 August 2002. Both cross sections were taken at latitudes of $31.0^{\circ} \mathrm{N}$ in the northern hemisphere. The images at Darwin are mapped to the northern hemisphere along the geomagnetic field line. The raw counts of the images are converted to an absolute intensity in Rayleighs using the calibration parameters of the imagers.

The eastward drift of the plasma bubbles is clearly seen at both Sata and Darwin from approximately 1630 UT as an oblique dark band in the keograms, indicating that these bubble structures are geomagnetically conjugate. From the gradient of this trace, the eastward drift speed 


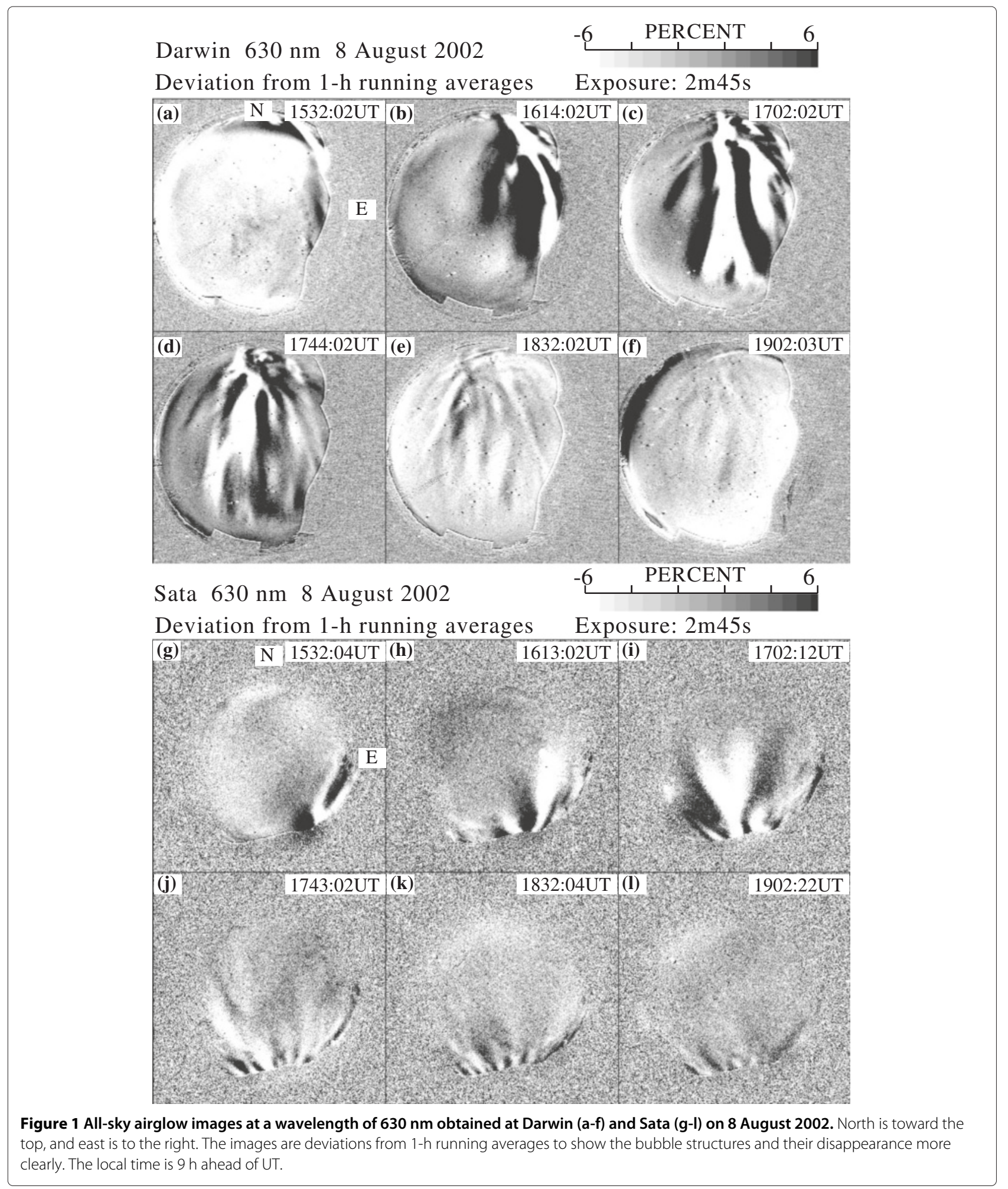

was estimated to be approximately $70 \mathrm{~m} / \mathrm{s}$ at 1630 to 1800 UT. After 1830 UT, the airglow intensity suddenly decreased, particularly at Darwin, where it decreased from more than 100 to approximately $50 \mathrm{R}$. The airglow intensity at Sata slightly decreased, by approximately $20 \mathrm{R}$, at the same time. This decrease of airglow intensity coincided with the disappearance of the bubble structures. We should note that the disappearance of the bubbles in the 


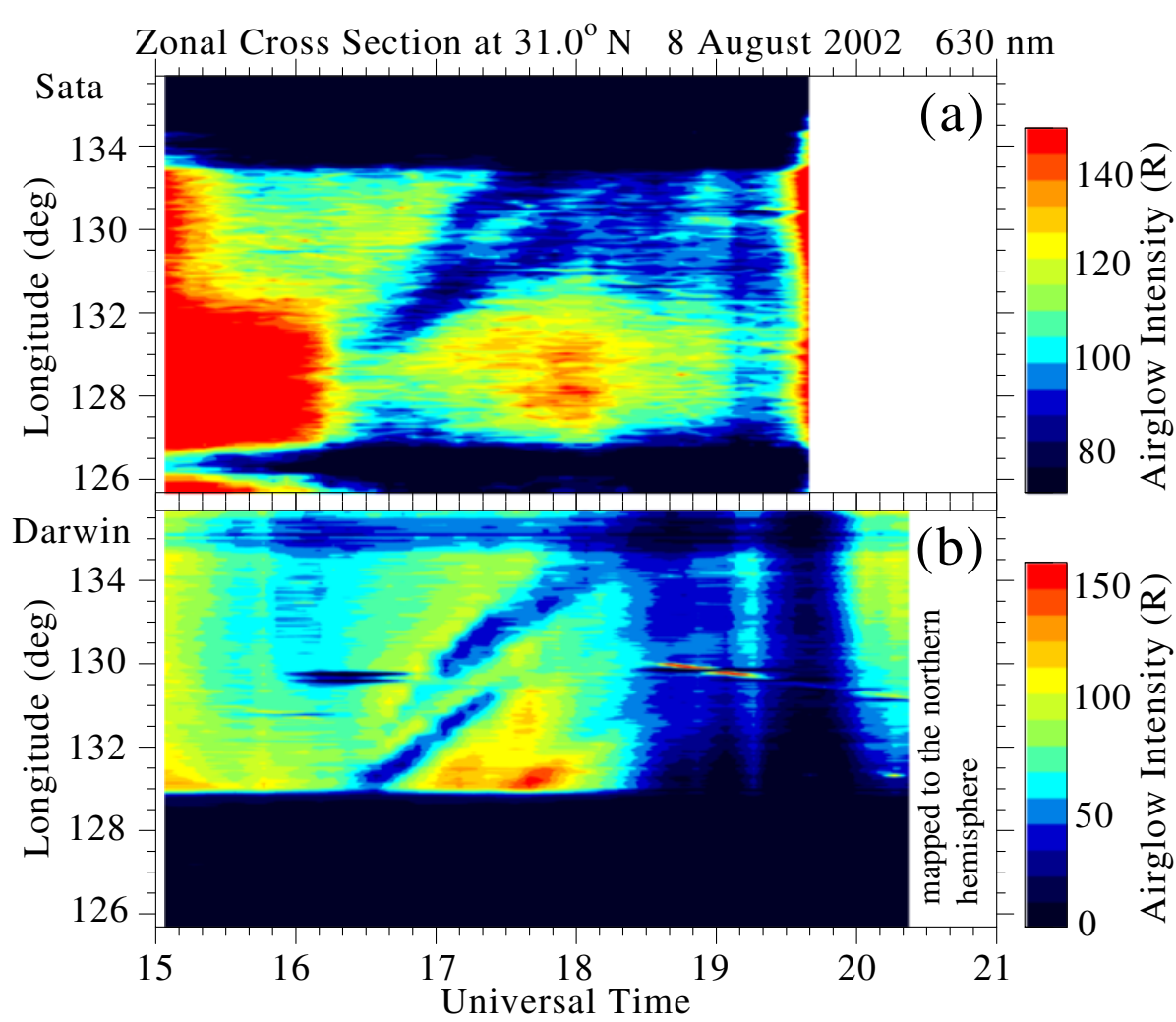

Figure 2 East-west cross sections (keograms) of 630-nm airglow images obtained at (a) Sata and (b) Darwin on 8 August 2002. The cross sections are taken at latitudes of $31.0^{\circ} \mathrm{N}$ in the northern hemisphere. The images for Darwin are mapped to the northern hemisphere along the geomagnetic field line.

airglow images is not due to the degradation of the image quality associated with the airglow intensity reduction; we had sufficient CCD counts to identify airglow structures even after 1830 UT. Notice also that the eastward drift velocity slowed down after $1830 \mathrm{UT}$, as can be seen in Animation 1.

To check the condition of the ionosphere during this event, we examined ionograms from these conjugate stations. At Darwin, 5-min cadence ionograms were available at the same site of the airglow imager from the Australian Ionospheric Prediction and Space Services ionosonde. Figure 3 shows representative ionograms for Darwin on this night. As the plasma bubble approached Darwin, a clear spread-F signature appeared from 1605 UT (see Figure 3b). The strong spread-F was still present at 2000 UT even after the plasma bubble had almost disappeared from the airglow images taken at Darwin.

Figure 4 shows some representative ionograms obtained at Yamagawa $\left(31.2^{\circ} \mathrm{N}, 130.6^{\circ} \mathrm{E}\right)$, Japan, which is about $20 \mathrm{~km}$ north of Sata. This ionosonde was operated by the National Institute of Information and Communications Technology (NICT), Japan, with a 15-min cadence.
As at Darwin, a clear spread-F signature appeared after 1700 UT as the plasma bubble approached Sata. The spread-F signature was still present at 2000 UT even after the plasma bubble had almost disappeared from the airglow images at Sata. This spread-F signature lasted at Yamagawa until approximately 2100 UT and was present even after the F-layer sunrise.

An enhancement in rate of TEC change index (ROTI) derived from GPS-TEC data was also observed around Yamagawa after 1700UT (NICT). ROTI is a standard deviation of time differential TEC in $5 \mathrm{~min}$, often used as the ionospheric irregularity index with a scale size of several tens of kilometers in plasma bubble structures (Nishioka et al. 2008). The ROTI enhancement disappeared before 2000 UT, different from the spread-F signatures in ionosondes. We speculate that this difference is not due to the difference of sensitive scale sizes between ROTI and ionosondes but due to the difference of physical parameters that cause spread-F and GPS ROTI. ROTI is the standard deviation of TEC variations for time scales of 30 to $300 \mathrm{~s}$. If the horizontal drift speed of ionospheric plasma is $100 \mathrm{~m} / \mathrm{s}$, this time scale gives the horizontal plasma structures with scale sizes of 3 to $30 \mathrm{~km}$, which 


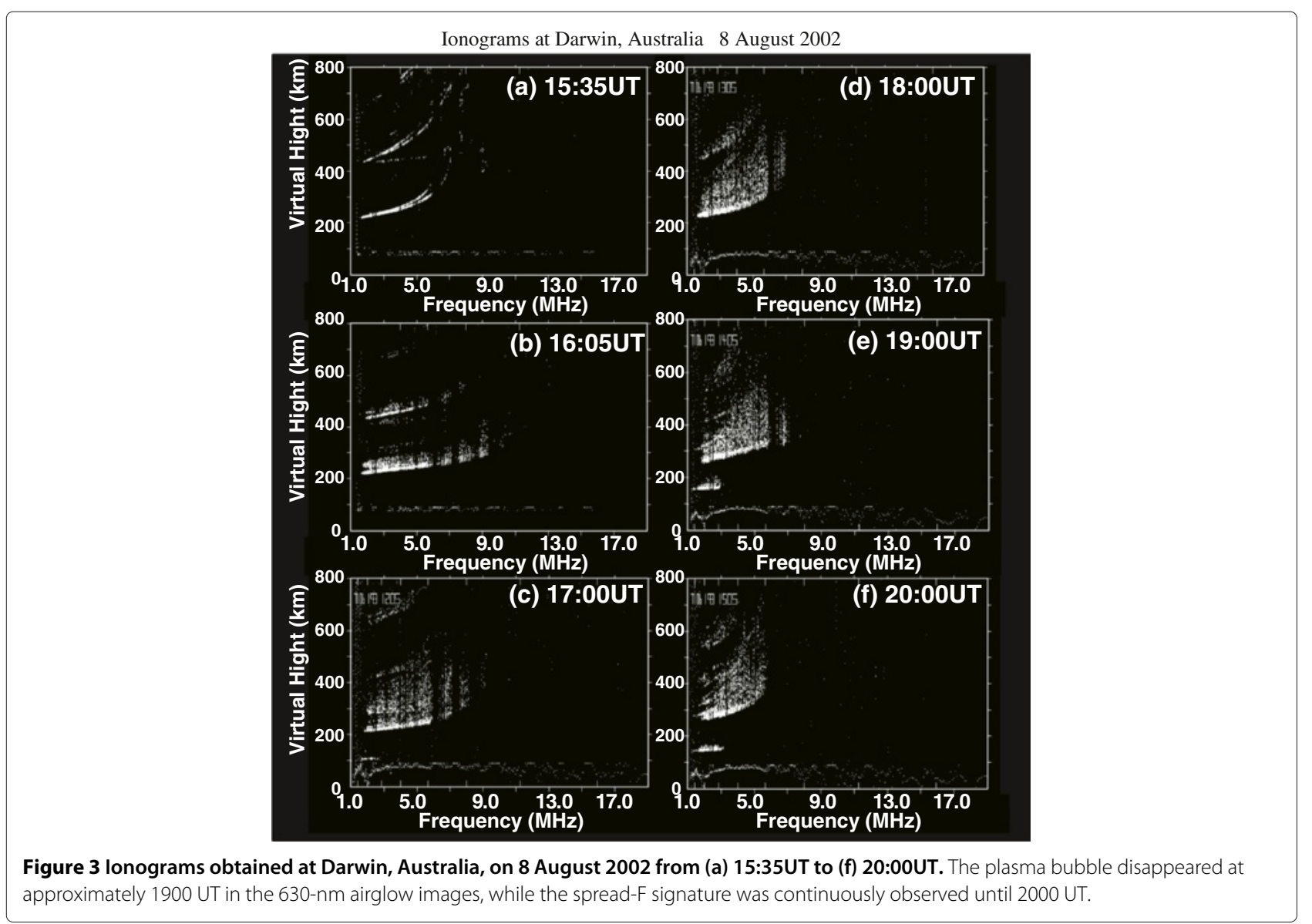

can also cause spread-F in the ionosonde signal. However, since ROTI is the variation of the TEC, it would be less sensitive to the bottomside variation of the ionosphere measured as spread-F.

Figure 5 shows a range-time display of the ionograms obtained at Darwin on 8 August 2002. This rangetime display was developed to investigate variations in the height of the nighttime $F$ layer by integrating the ionosonde echoes on the ionograms over frequency (e.g., Lynn et al. 2006; 2011). Associated with the presence of the plasma bubble in the airglow images, which is indicated by the horizontal yellow arrow, the spread-F signature can be seen after 1600 UT in the range direction. This spread-F signature remains even after the bubble disappearance at $1900 \mathrm{UT}$ and lasts until sunrise at approximately $2200 \mathrm{UT}$. It is interesting that the F-layer virtual height clearly increased from approximately 200 to approximately $260 \mathrm{~km}$ at 1800 to 1900 UT when the bubble disappeared from the airglow images. This sudden F-layer rise is probably the cause of the sudden decrease of the 630-nm airglow intensity, because the 630-nm airglow intensity is proportional to the $\mathrm{O}^{+}$density (= F-layer plasma density) and the $\mathrm{O}_{2}$ density. As the F-layer height rises, the ambient $\mathrm{O}_{2}$ density decreases so that the 630-nm intensity also decreases.

To see whether this sudden F-layer height increase at Darwin also occurred at the conjugate point in the northern hemisphere, we plotted F-layer virtual height at $2 \mathrm{MHz}$, as obtained from the ionograms taken at Yamagawa, Japan, near Sata (see Figure 6). The virtual height of the F layer at Yamagawa is approximately stable at 250 to $270 \mathrm{~km}$ from 1500 to 2000 UT even after the disappearance of the plasma bubble from the airglow images.

Figure 7 shows the eastward and northward wind velocity in the thermosphere measured by a Fabry-Perot interferometer (FPI) at Shigaraki $\left(34.9^{\circ} \mathrm{N}, 136.1^{\circ} \mathrm{E}\right)$, Japan, which is approximately $660 \mathrm{~km}$ northeast of Sata. The FPI measured the thermospheric neutral wind through independent observations of the Doppler shift of the 630-nm airglow emission lines for two interference fringes (inner and outer) with a time resolution of $15 \mathrm{~min}$ (Shiokawa et al. 2003a). Although the count rate was not very high on this night, we could determine the wind velocities throughout the night. The wind gradually shifted from approximately $100 \mathrm{~m} / \mathrm{s}$ eastward to approximately $100 \mathrm{~m} / \mathrm{s}$ southward from 11 UT (20 LT) to 19 UT (04 LT), which 

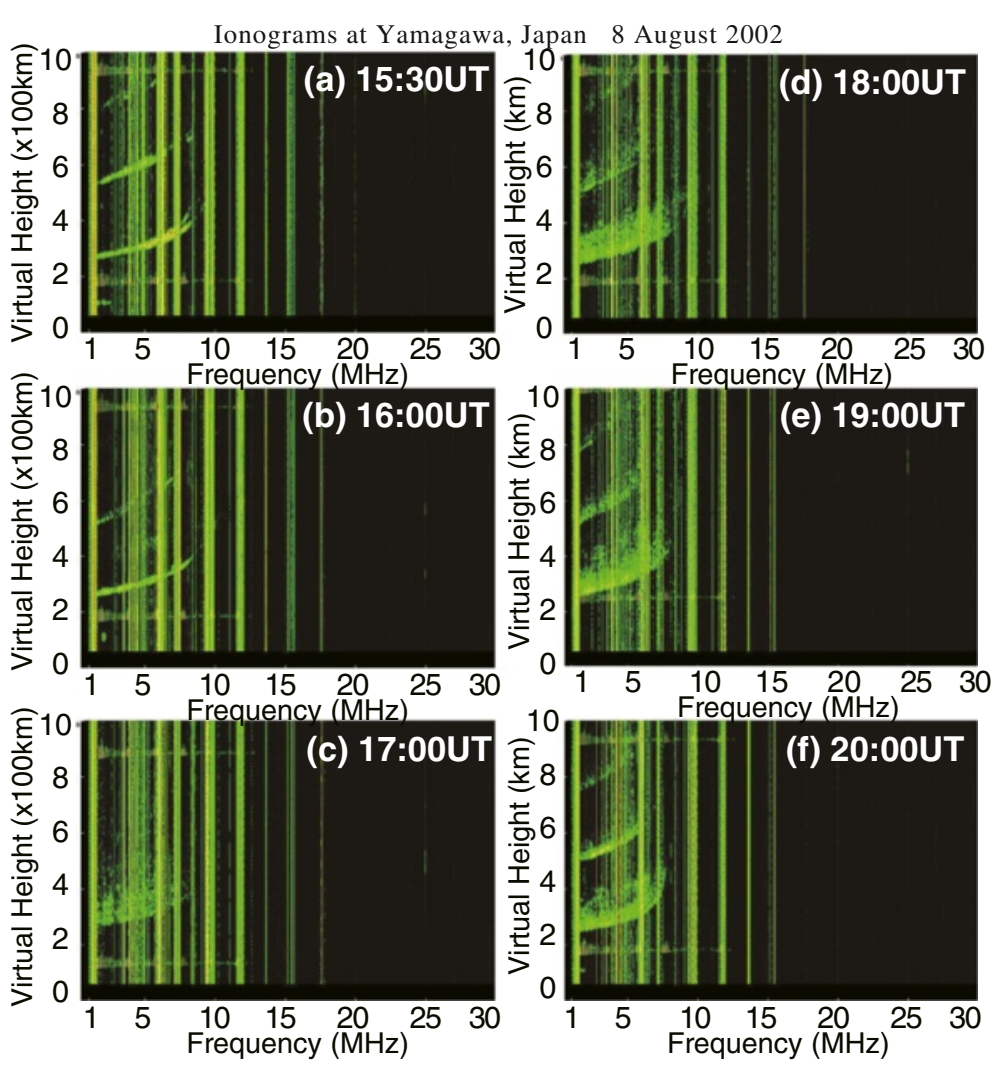

Figure 4 lonograms obtained at Yamagawa, Japan, near Sata on 8 August 2002 from (a) 15:30UT to (f) 20:00UT.

is a typical nighttime variation of thermospheric tides. No sudden change of the wind velocity is seen at the time of the sudden F-layer height rise over Darwin at 18 to 19 UT.

\section{Results and discussion}

We have described a conjugate observation of plasma bubble disappearance in 630-nm airglow images at Darwin and Sata. The observed features can be summarized as follows.

(1) The plasma bubble appeared from the west of Darwin and Sata at 1530 UT (0030 LT), drifting eastward with a speed of approximately $70 \mathrm{~m} / \mathrm{s}$, as determined from the east-west keogram in Figure 2.

(2) The bubble rapidly vanished equatorward at 1800 to 1900 UT (0300 to 0400 LT) and almost disappeared from the airglow images after 1930 UT.

(3) The eastward drift of the bubble slowed down during the disappearance.

(4) At Darwin, the F-layer virtual height suddenly increased from approximately 200 to approximately 260 $\mathrm{km}$ at 1800 to $1900 \mathrm{UT}$, when the bubble disappeared. Such an increase in F-layer height was not observed at the conjugate point at Yamagawa.
(5) The airglow intensity at Darwin suddenly decreased from more than 100 to approximately $50 \mathrm{R}$ at approximately 1830 UT. The airglow intensity at Sata also slightly decreased by approximately $20 \mathrm{R}$ at the same time.

(6) Spread-F signatures associated with the plasma bubble appearance were observed at both Darwin and Yamagawa (near Sata). The spread-F signatures lasted until sunrise at both stations and were present even after the disappearance of the bubble from the airglow images at 1900 UT. This probably corresponds to some faint bubble structures in the airglow images, which remain recognizable until the end of the observation (2020 UT at Darwin and 1937 UT at Sata).

(7) The thermospheric neutral wind at Shigaraki (approximately $660 \mathrm{~km}$ northeast of Sata) shows ordinary variation of thermospheric tides from approximately 100 $\mathrm{m} / \mathrm{s}$ eastward in the evening to approximately $100 \mathrm{~m} / \mathrm{s}$ southward in the morning.

The sudden F-layer height rise at 1800 to 1900 UT seems to be the key to understanding the observed bubble disappearance. There are two possible causes for a sudden increase in F-layer height: an eastward electric field and an equatorward neutral wind in the thermosphere. A similar height rise was not observed at Yamagawa, which 


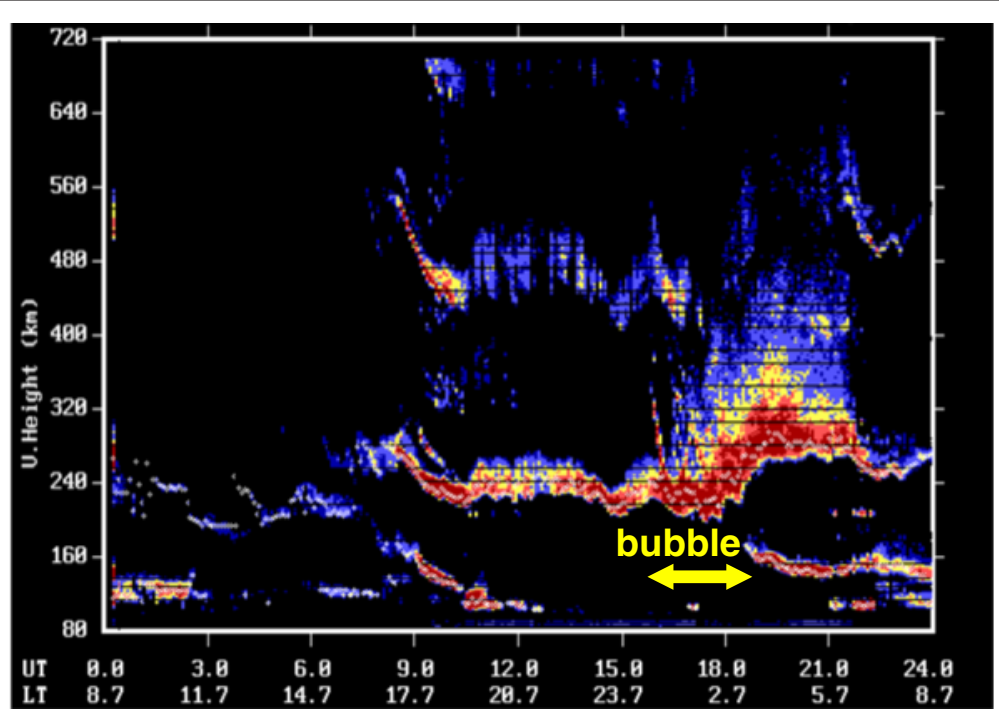

Figure $\mathbf{5}$ Range-time display of the ionograms obtained at Darwin from $\mathbf{0 0}$ to $\mathbf{2 4}$ UT on $\mathbf{8}$ August 2002. The horizontal arrow indicates the time interval (approximately 1600 to 1900 UT) during which the plasma bubble was observed in the airglow images.

is the geomagnetically conjugate point of Darwin, though the airglow intensity slightly decreased at Sata at 1830 UT. Thus, the eastward electric field is not likely to be the cause of the sudden rise of the F-layer at Darwin, since the electric field would be uniform over the northern and southern hemispheres along the geomagnetic field line. We conclude that the rise at Darwin was caused by a sudden enhancement of the equatorward neutral wind that pushed the ionospheric plasma up along the geomagnetic field line. However, such an enhancement of the equatorward neutral wind was not observed in the thermospheric wind data at Shigaraki (Figure 7).
What caused the enhancement of the equatorward neutral wind at Darwin? This night was geomagnetically quiet with $\mathrm{Kp}$ indices of $2-$ at 12 to $15 \mathrm{UT}$ and $1+$ at 15 to 18 UT. A small substorm took place with a maximum $A E$ index of approximately $250 \mathrm{nT}$ at $1400 \mathrm{UT}$. Figure 8 shows north-south cross sections (keograms) of 630-nm airglow images obtained at (a) Sata and (b) Darwin on 8 August 2002. This keogram was made by taking latitudinal cross sections including zenith of these stations for airglow images mapped onto the geographical coordinates. Before the decrease in airglow intensity at Darwin at $1830 \mathrm{UT}$, there is an enhanced airglow region propagating

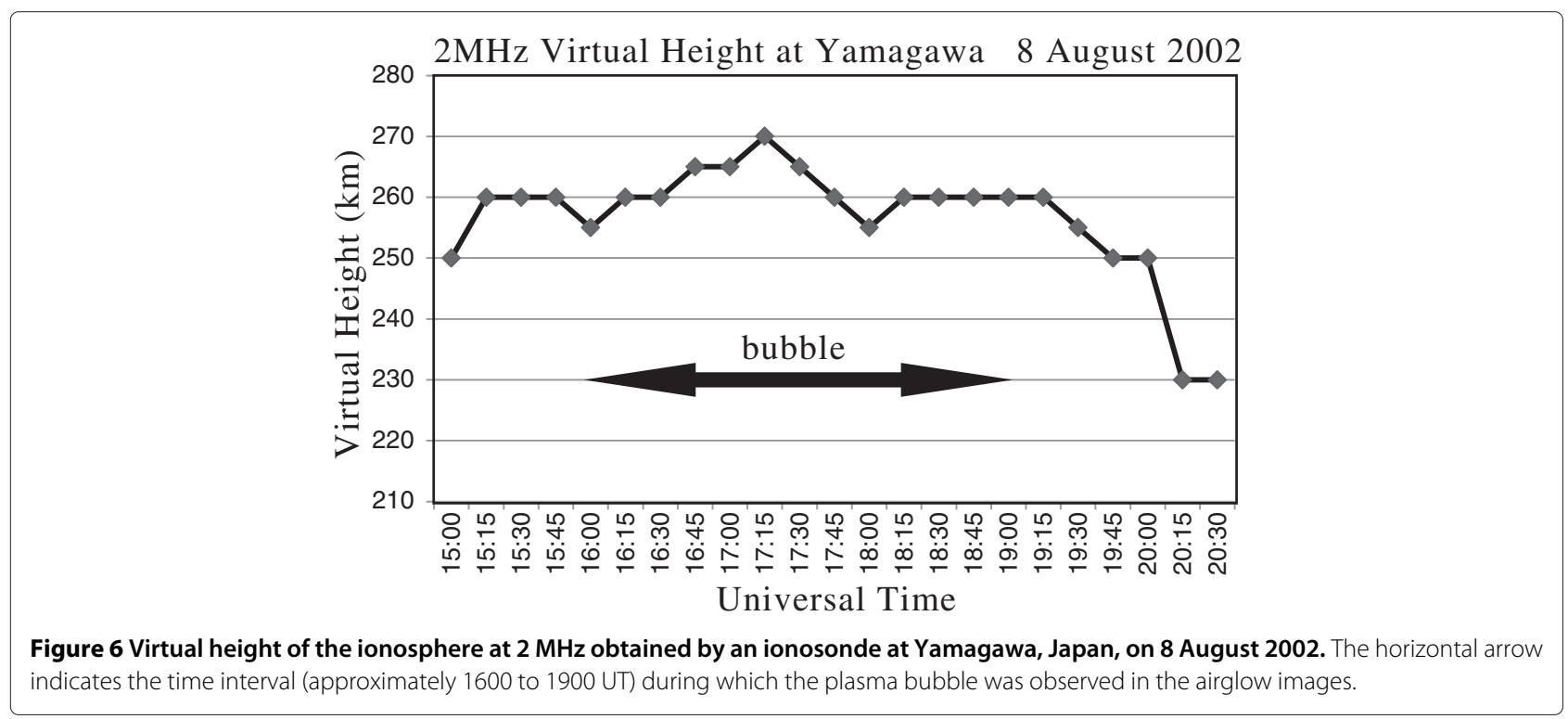




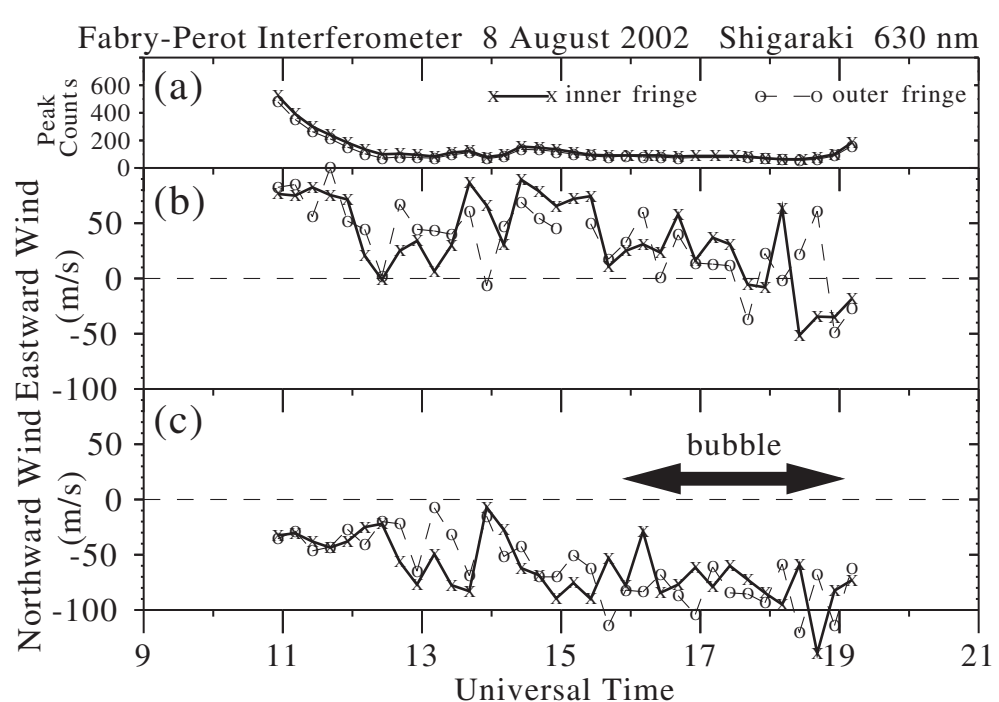

Figure 7 Thermospheric neutral wind velocities measured by a Fabry-Perot interferometer at Shigaraki, Japan. Eastward (b) and northward (c) wind were measured through the Doppler shift of the 630-nm airglow emission at altitudes of 200 to $300 \mathrm{~km}$. The count rate (per pixel) of the interferometer is also shown in (a) to indicate the data quality. Two interference fringes (inner and outer) were used independently to determine these wind velocities. The horizontal arrow indicates the time interval (approximately 1600 to 1900 UT) during which the plasma bubble was observed in the airglow images.

northward (equatorward) from 1730 to 1830 UT. This enhanced airglow may correspond to the gradual F-layer height decrease from 1600 to 1800 UT, which can be seen in Figure 5. After this enhanced airglow, a region of decreased airglow appeared after 1800 UT at the southern edge of the keogram at Darwin and propagated northward (equatorward) with a speed of approximately 170 $\mathrm{m} / \mathrm{s}$. At Sata in Figure $8 \mathrm{a}$, the airglow intensity gradually decreases from 15 (midnight) to 19 UT as seen in usual night, and equatorward-moving structures were not clearly observed. This equatorward motion of the reduced airglow regions at Darwin is likely to be caused by a largescale traveling atmospheric disturbance (TAD). An equatorward neutral winds in the thermosphere associated with the large-scale TAD could cause the reduction of the 630-nm airglow intensity by increasing the F-layer height along the geomagnetic field line. This propagating feature in the keogram also indicates that this airglow reduction and associated F-layer height rise were not caused by global eastward electric field penetrating from the magnetosphere, since such electric field penetration propagates with a speed of light. The fact that the observed TAD does not have geomagnetic conjugacy also suggest that this is a neutral wind variation as a TAD.

The large-scale TADs have also been referred as large-scale traveling ionospheric disturbances (LSTIDs) (e.g., Hunsucker, 1982). The LSTIDs characterized by variations of the meridional neutral wind have been identified in the 630-nm airglow images and F-layer height variations (Shiokawa et al. 2002; 2003b; 2007), though these previous LSTIDs were observed during strong geomagnetic storms. Using 45 months of GPS-TEC images obtained in Japan, however, Tsugawa et al. (2004) reported that $28 \%$ of LSTIDs are observed during magnetically quiet times with $K p<3$. LSTIDs are not connected electromagnetically through the geomagnetic field but are generated by atmospheric gravity waves propagating to the equator independently in the two hemispheres as TADs (Tsugawa et al. 2006).

In order to obtain a larger scale view of the TAD propagation, we plotted relative variations of h'F obtained by the ionosondes in southern Australian latitudes in Figure 9. The stations are plotted from low (top) to high (bottom) latitudes. The F-layer height rise at Darwin is identified as the h'F increase at 1710 to 1840 UT. Similar h'F increase was observed at Townsville, about $7^{\circ}$ higher latitudes, at $1650 \mathrm{UT}$, indicating that this F-layer height rise propagated from high to low latitudes, as shown in the airglow keogram in Figure 8. At latitudes higher than Norfolk, corresponding F-layer height rise was not clearly identified. Thus, the observed TAD at Darwin would not be generated by auroral zone energy input at high latitudes but by some dynamical variations in the thermosphere at middle latitudes.

The observed bubble disappearance was associated with the equatorward neutral-wind enhancement and F-layer height rise at Darwin. It is still not clear how the equatorward neutral wind caused the bubble disappearance. The collisional transport of ionospheric plasma by neutrals across the geomagnetic field line seems to be too slow 


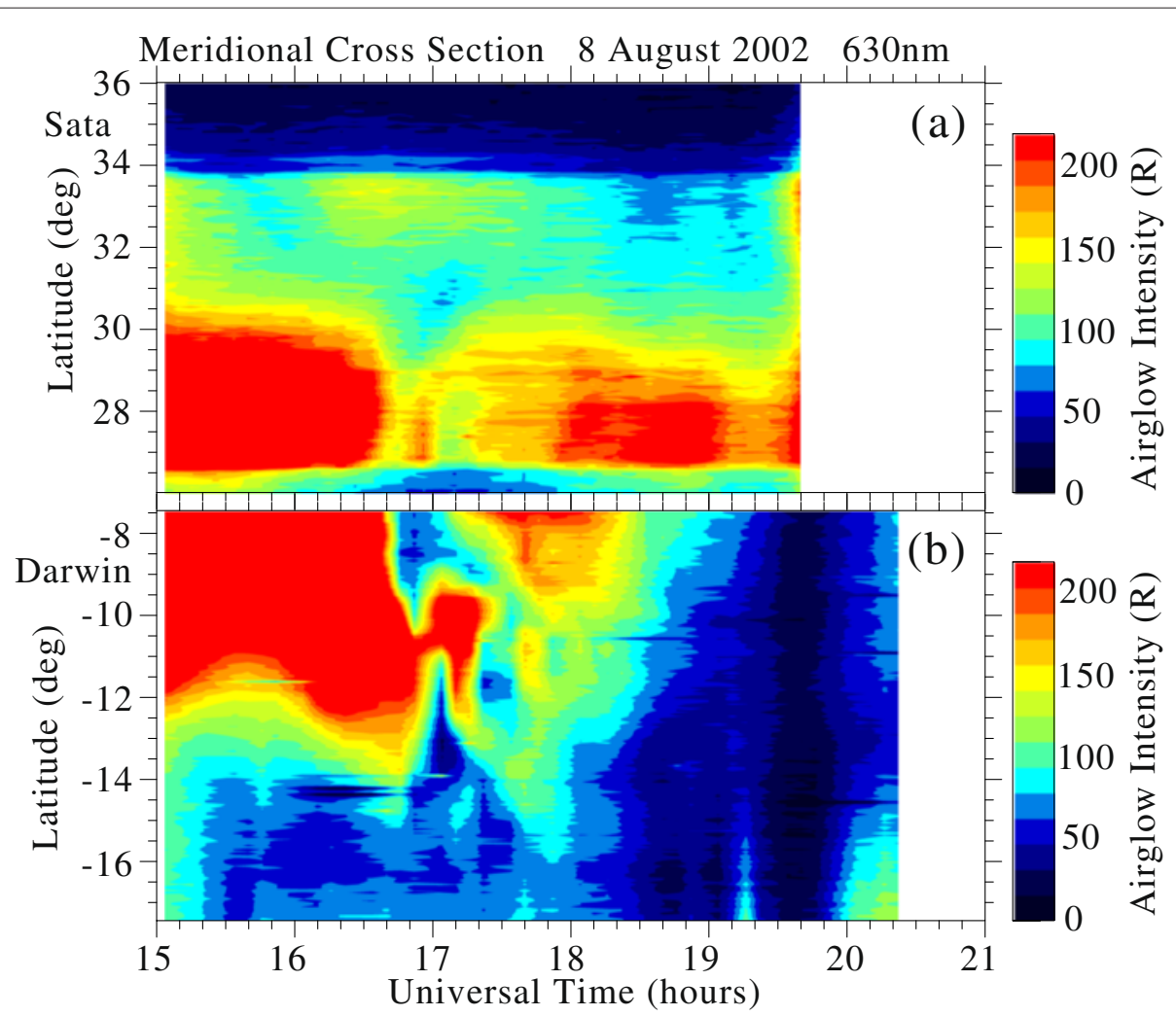

Figure 8 North-south cross sections (keograms) of 630-nm airglow images obtained at (a) Sata and (b) Darwin on 8 August 2002. The cross sections are taken at the longitudes of Sata and Darwin, respectively.

to create the observed disappearance. The F-layer height rise may cause an apparent disappearance of the plasma bubble in the 630-nm airglow images, because the 630$\mathrm{nm}$ airglow layer is located at the bottom of the F-layer at 200 to $300 \mathrm{~km}$. This idea also explains why the spread$\mathrm{F}$ signature in the ionograms did not disappear even after the disappearance of the bubble in the 630-nm airglow images. To try to see the bubble structure at the F-layer peak height of approximately $400 \mathrm{~km}$, we checked the images of 777.4-nm airglow which comes from the F-layer peak height. However, the 777.4-nm airglow was too weak to see the bubble structure on this night.

It should be noted, however, that even if the F-layer height increase causes a decrease of the 630-nm airglow intensity, the contrast of the bubble structure in the airglow should remain unless diffusion of plasma across the field line occurs. Thus, we should observe the bubble structure in the images shown in Figure 1, which depicts the deviation from 1-h running averages. As we noted before, the count rate for the images with a weakened intensity of approximately $50 \mathrm{R}$ was still high enough to identify bubble structures in the deviation images. Thus, the idea that the rise of the F-layer caused the apparent disappearance of bubbles in the 630-nm airglow images is not supported.
The other possibility is that plasma density enhancement associated with ionospheric sunrise caused the observed bubble disappearance, because the present observation took place in the morning time. To investigate this possibility, we have checked the sunrise timings. The sunrise times at 500-km height at (1) Darwin and (2) Sata and at (3) apex height $\left(1,280 \mathrm{~km}\right.$ at $8.1^{\circ} \mathrm{N}$, $\left.131.9^{\circ} \mathrm{E}\right)$ and (4) conjugate point $(500-\mathrm{km}$ height $)$ of field line traced from $250-\mathrm{km}$ height of Darwin are (1) 2004, (2) 1848, (3) 1844, and (4) 1900 UT, respectively. Because the disappearance of the plasma bubble had started at approximately $1800 \mathrm{UT}$, it is not likely that the ionospheric sunrise affected the disappearance of the bubble.

We also checked another example of morning-time plasma bubble observed at Darwin on 17 March 2002 (not shown). The plasma bubble was observed until 2030 UT (0530 LT). The sunrise time of $300-\mathrm{km}$ and $500-\mathrm{km}$ height at Darwin was 2013 and 1953 UT on this night. Thus, the bubble was clearly observed even after the $300-\mathrm{km}$ height sunrise. This is probably because these sunrise times are calculated from the simple geometry of the earth's surface to the sun without considering absorption of the solar ultraviolet emission in the lower atmosphere. From these considerations, we conclude that the effect of sunrise and 


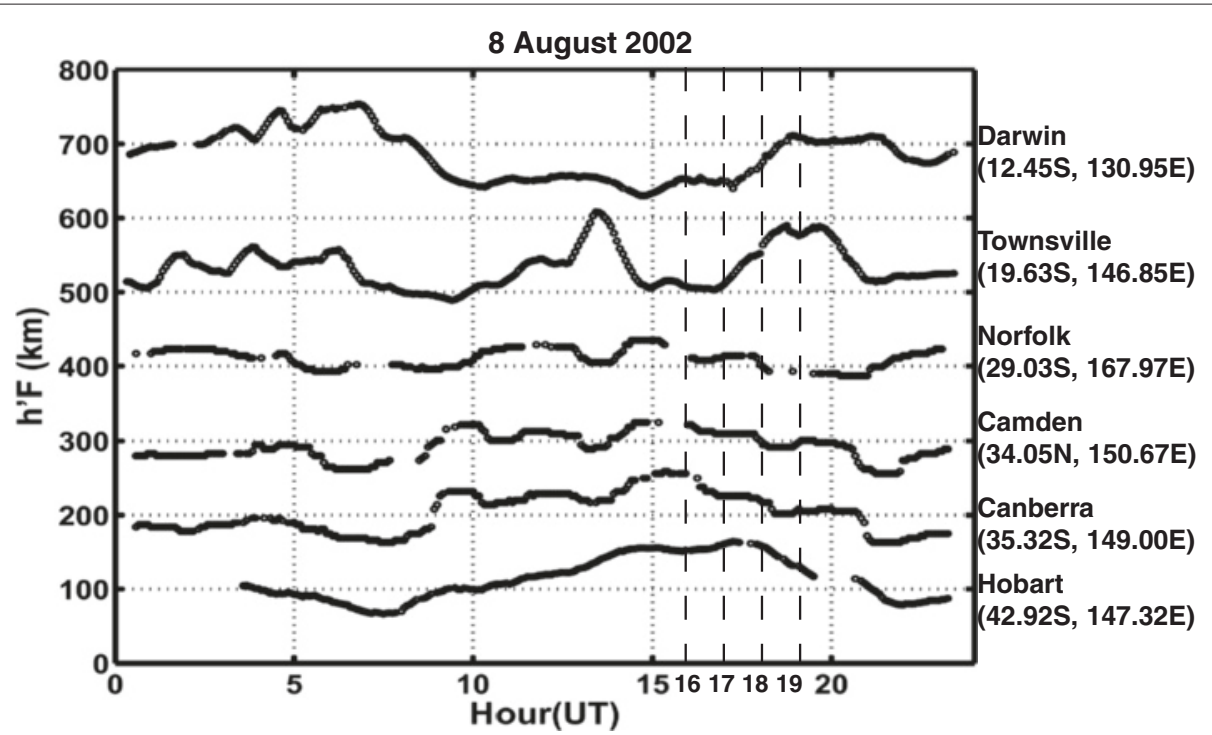

Figure 9 lonospheric $h^{\prime} F$ height variations observed at ionosondes in southern Australian latitudes on 8 August 2002. The stations are shown from low (top) to high (bottom) latitudes. Only relative variations of h'F are plotted with shifting offset.

associated plasma density enhancement is not the cause of the bubble disappearance for the present event.

In Figure 10, we show two possible mechanisms that can cause the observed bubble disappearance associated with the enhancement of equatorward neutral wind by an TAD. Figure 10a is the mechanism of F-region dynamo, which is based on the description by Miller and Kelley et al. (1997). The enhanced equatorward wind causes eastward $u \times B$ drift of ions to flow Pedersen current $J_{p}$. However, since the nighttime $E$ region has no conductivity, the Pedersen current cannot flow into the $\mathrm{E}$ region to close the current circuit $\left(J_{p}=\Sigma_{p}(E+u \times B)=0\right.$, where $\Sigma_{p}$ is the Pedersen conductivity). As a result, charge separation and associated electric field $E$ will be created, causing equatorward $E \times B$ drift of plasma in the same speed of neutral wind $u$. Because of this meridional motion of plasma perpendicular to the ambient magnetic field, the plasma bubble will be filled by ambient high-density plasma. This happens because the TAD has a clear equatorward boundary (phase front) of the equatorward wind enhancement.

The other possible mechanism, polarization electric field, is shown in Figure 10b. If there is a finite Pedersen current $J_{p}$, which has a perpendicular component to the TAD phase front, it would cause polarization electric field $E$ due to inhomogeneity of Pedersen conductivity $\Sigma_{p}$ in the $\mathrm{F}$ layer. This inhomogeneity is caused by the F-layer height increase (decrease) due to equatorward (poleward) neutral wind. The electric field causes $E \times B$ drift of F-layer plasma to fill the plasma bubbles by ambient highdensity plasma. It should be noted that the two mechanisms, F-region dynamo effect and polarization electric field, can occur simultaneously.
For both cases, the equatorward TAD motion would cause disappearance of the plasma bubble from high to low latitudes, which was identified as the equatorward disappearance of the bubbles in Animations 1 and 2. If we have a uniform electric field over the considered area, the bubbles move with the ambient plasma due to the $E \times B$ drift and the bubble structure would be maintained. For the present case, however, the electric field is induced by the localized enhancement of neutral wind in Figure 10a or localized polarization in Figure 10b. We consider that these spatial inhomogeneities propagating equatorward are able to cause relative motion of plasma across the bubble boundary.

In the mechanism of Figure 10a, the equatorward neutral wind causes upward motion of the plasma along geomagnetic field line, causing decreasing airglow intensity as observed at Darwin. On the other hand, the $E \times B$ drift perpendicular to the magnetic field is equatorward and downward, possibly resulting in the increase of the airglow. In the actual situation, the two processes should happen simultaneously, and the downward $E \times B$ drift motion can be smaller than the upward plasma motion along geomagnetic field line, resulting in the observed airglow depletion at Darwin. If this westward electric field is mapped to the northern hemisphere to Sata, however, it should cause downward $E \times B$ drift resulting in the airglow enhancement. This process contradicts to the observed decrease of airglow intensity at 1830 UT at Sata. Thus, the electric field by the F-region dynamo process in Figure 10a may not be significant for the present case.

In the mechanism of Figure 10b, the polarization electric field has an eastward component. This electric field causes upward $E \times B$ drift, resulting in the decrease of 


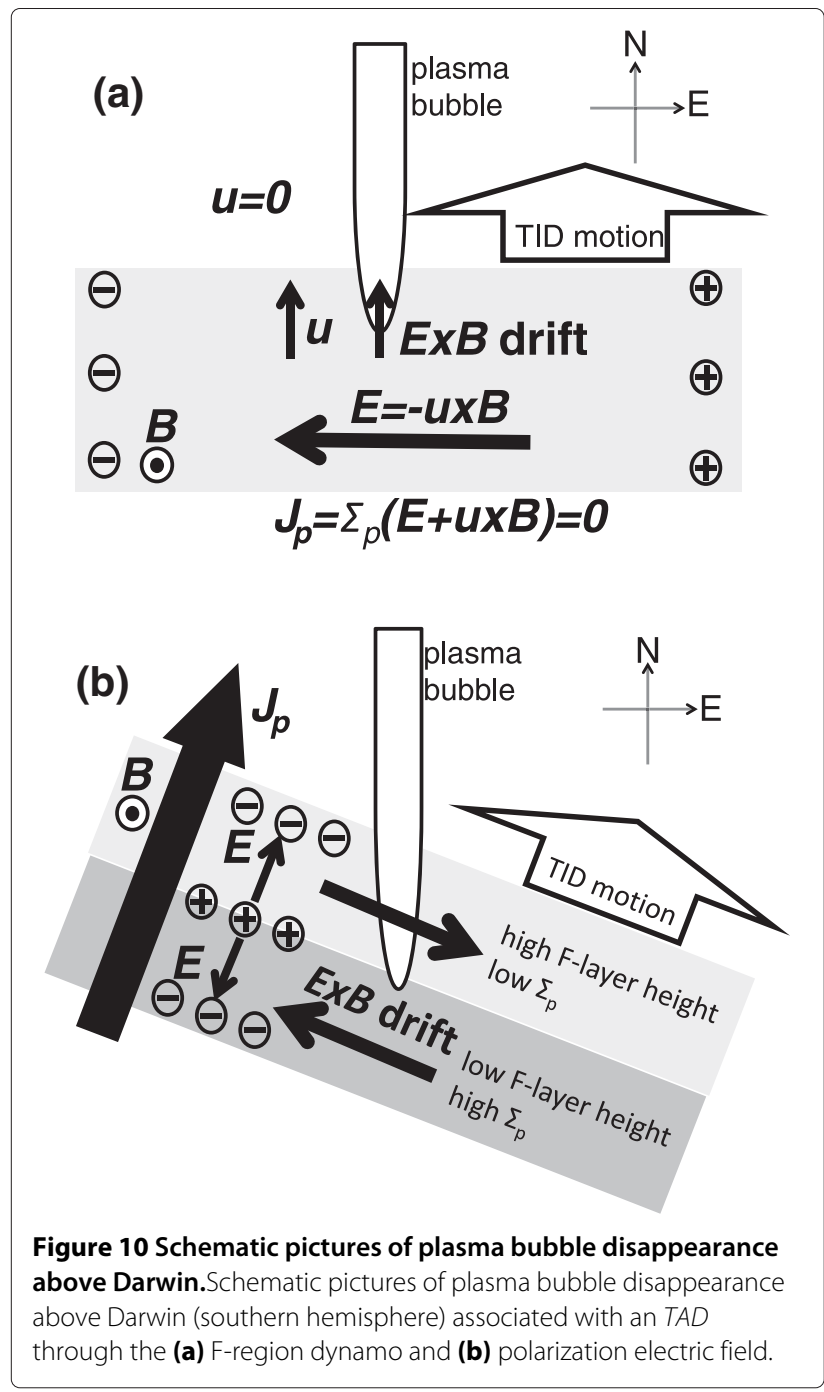

airglow intensity at both hemispheres, which is consistent with the present observation. Thus, we conclude that the polarization electric field shown in Figure 10b is more likely the cause of the observed bubble disappearance.

\section{Conclusions}

We report the simultaneous observation of the disappearance of a plasma bubble at the geomagnetically conjugate points of Darwin and Sata at magnetic latitudes of $21^{\circ}$ to $22^{\circ}$ on 8 August 2002. The plasma bubble disappeared equatorward at 1800 to 1900 UT (0300 to $0400 \mathrm{LT}$ ) in the $630-\mathrm{nm}$ airglow images. At Darwin, the F-layer virtual height suddenly increased from approximately 200 to approximately $260 \mathrm{~km}$ at the time of the bubble's disappearance, but such an F-layer height increase was not observed at Yamagawa. This indicates that the F-layer rise was not caused by the eastward electric field but by an enhancement of the equatorward neutral wind over Darwin. From the meridional keogram of the 630-nm airglow at Darwin, we conclude that this enhancement of the equatorward neutral wind in the thermosphere was caused by an equatorward-propagating TAD. We considered the F-region dynamo and polarization electric field associated with this TAD as the cause of the observed bubble disappearance through the plasma drift across the geomagnetic field. We speculate that the latter mechanism, the polarization electric field, is more likely the cause because of the simultaneous depletion of airglow intensity at Sata. The present observation indicates that the interaction of the equatorial plasma bubbles with ionospheric and thermospheric waves can cause dissipation of the bubble structure, as suggested by Otsuka et al. (2012) for the interaction of bubbles with mid-latitude MSTIDs.

\section{Additional files}

Additional file 1: Animation 1. A movie of the all-sky 630-nm airglow images obtained at Darwin, Australia, from 1002 to 2020 UT on 8 August 2002. North is upward, and east is to the left.

Additional file 2: Animation 2. A movie of the all-sky 630-nm airglow images obtained at Sata, Japan, from 1102 to 1937 UT on 8 August 2002. North is upward, and east is to the left.

\section{Competing interests}

The authors declare that they have no competing interests.

\section{Authors' contributions}

KS conceived and coordinated this study, analyzed the data, interpreted the results, and wrote the first draft of the paper. YO analyzed part of the airglow data. KJL and PW provided ionosonde data in Australia. KJL also provided range-time plots of ionograms at Darwin. TT provided ionosonde and GPS-TEC data in Japan. All coauthors contributed to the revision of the draft manuscript and improvement of the discussion. All authors read and approved the final manuscript.

\section{Acknowledgements}

We thank Y. Katoh, M. Satoh, T. Katoh, and K. Hidaka of the Solar-Terrestrial Environment Laboratory (STEL), Nagoya University, for their kind help with airglow imaging observations at Sata and Darwin. The airglow data used in this paper are available from STEL. The ionosonde data at Yamagawa were provided by the WDC for lonosphere and Space Weather, Tokyo, National Institute of Information and Communications Technology. We are thankful to the World Data Centre (WDC) of IPS Radio and Space Services, Bureau of Meteorology of Australia for the provision of the ionosonde data. This work was supported by the JSPS Core-to-Core Program, B. Asia-Africa Science Platforms. This work was also supported by JSPS Grants-in-Aid for Scientific Research (11440145, 13573006, 20244080, and 25247080) and the IUGONET Project from MEXT, Japan.

\section{Author details}

${ }^{1}$ Solar-Terrestrial Environment Laboratory, Nagoya University, Furo-cho, Chikusa-ku, 464-8601 Nagoya, Japan. ${ }^{2}$ Ionospheric Systems Research, 16 Heritage Drive, 4566 Noosaville, Australia. ${ }^{3}$ Bureau of Meteorology, IPS Radio and Space Services, 300 Elizabeth St., 2000 Surry Hills, NSW, Australia. ${ }^{4}$ Strategic Planning Department, National Institute of Information and Communications Technology, 4-2-1 Nukui-Kitamachi, 184-8795 Koganei, Tokyo, Japan.

Received: 29 March 2014 Accepted: 3 February 2015

Published online: 26 March 2015 


\section{References}

Aarons J, Mendillo M, Lin B, Colerico M, Beach T, Kintner P, Scali J, Reinisch B, Sales G, Kudeki E (1999) Equatorial F region irregularity morphology during an equinoctial month at solar minimum. Space Sci Rev 87:357-386

Abdu MA, Batista IS, Reinisch BW, de Souza JR, Sobral JHA, Pedersen TR, Medeiros AF, Schuch NJ, de Paula ER, Groves KM (2009) Conjugate Point Equatorial Experiment (COPEX) campaign in Brazil: Electrodynamics highlights on spread F development conditions and day-to-day variability. J Geophys Res 114:A4. doi:10.1029/2008JA013749

Basu S, Kudeki E, Basu Su, Valladares CE, Weber EJ, Zengingonul HP, Bhattacharyya S, Sheehan R, Meriwether JW, Biondi MA, Kuenzler H, Espinoza J (1996) Scintillations, plasma drifts, and neutral winds in the equatorial ionosphere after sunset. J Geophys Res 101:A12,26795-26809. doi:10.1029/96JA00760

Fejer BG, Scherliess L, ce Paula ER (1999) Effects of the vertical plasma drift velocity on the generation and evolution of equatorial spread F. J Geophys Res 104:19859-19869

Hunsucker RD (1982) Atmospheric gravity waves generated in the high-latitude ionosphere: A review. Rev Geophys Space Phys 20:293-315

Kelley MC (1989) The Earth's ionosphere, Plasma Physics and Electrodynamics. Academic Press, San Diego, California

Lynn KJW, Harris TJ, Sjarifudin M (2006) Relationships between electron density, height and sub-peak ionospheric thickness in the night equatorial ionosphere. Ann Geophys 24:1343-1353. doi:10.5194/angeo-24-1343-2006

Lynn KJW, Otsuka Y, Shiokawa K (2011) Simultaneous observations at Darwin of equatorial bubbles by ionosonde-based range/time displays and airglow imaging. Geophys Res Lett 38:L23101. doi:10.1029/2011GL049856

Makela JJ, Kelley MC (2003) Field-aligned 777.4-nm composite airglow images of equatorial plasma depletions. Geophys Res Lett 30(8):1442. doi:10.1029/2003GL017106

Martinis C, Mendillo M (2007) Equatorial spread F-related airglow depletions at Arecibo and conjugate observations. J Geophys Res 112:A10. doi:10.1029/2007JA012403

Makela JJ, Kelley MC, Nicolls MJ (2006) Optical observations of the development of secondary instabilities on the eastern wall of an equatorial plasma bubble. J Geophys Res 111:A09311. doi:10.1029/2006JA011646

Mendillo M, Baumgardner J (1982) Airglow characteristics of equatorial plasma depletions. J Geophys Res 87:7641-7652

Miller CA, Kelley MC (1997) Horizontal plasma flow at midlatitudes: More mechanisms and the interpretation of observations. J Geophys Res 102(A6):11,549-11,555. doi:10.1029/96JA03842

Nishioka M, Saito A, Tsugawa T (2008) Occurrence characteristics of plasma bubble derived from global groundbased GPS receiver networks. J Geophys Res 113:A05301. doi:10.1029/2007JA012605

Ogawa T, Sagawa E, Otsuka Y, Shiokawa K, Immel TI, Mende SB, Wilkinson P (2005) Simultaneous ground- and satellite-based airglow observations of geomagnetic conjugate plasma bubbles in the equatorial anomaly. Earth Planets Space 57:385-392

Otsuka Y, Shiokawa K, Ogawa T, Wilkinson P (2002) Geomagnetic conjugate observations of equatorial airglow depletions. Geophys Res Lett 29:15. doi:10.1029/2002GL015347

Otsuka Y, Shiokawa K, Ogawa T (2012) Disappearance of equatorial plasma bubble after interaction with mid-latitude medium-scale traveling ionospheric disturbance. Geophys Res Lett 39:L14105. doi:10.1029/2012GL052286

Park J, Noja M, Stolle C, Luhr H (2013) The lonospheric Bubble Index deduced from magnetic field and plasma observations onboard Swarm. Earth Planets Space 65:11,1333-1344. doi:10.5047/eps.2013.08.005

Rohrbaugh RP, Hanson WB, Tinsley BA, Cragin BL, McClure JP, Broadfoot AL (1989) Images of transequatorial bubbles based on field-aligned airglow observations from Haleakala in 1984-1986. J Geophys Res 94:6763-6770

Shiokawa K, Katoh Y, Satoh M, Ejiri MK, Ogawa T, Nakamura T, Tsuda T, Wiens RH (1999) Development of optical mesosphere thermosphere imagers (OMTI). Earth Planets Space 51:887-896

Shiokawa K, Katoh Y, Satoh M, Ejiri MK, Ogawa T (2000) Integrating-sphere calibration of all-sky cameras for nightglow measurements. Adv Space Sci 26:1025-1028

Shiokawa K, Otsuka Y, Ogawa T, Balan N, Igarashi K, Ridley AJ, Knipp DJ, Saito A, Yumoto K (2002) A large-scale traveling ionospheric disturbance during the magnetic storm of September 15, 1999. J Geophys Res 107(A6):1088. doi:10.1029/2001JA000245
Shiokawa K, Kadota T, Otsuka Y, Ogawa T, Nakamura T, Fukao S (2003a) A two-channel Fabry-Perot interferometer with thermoelectric-cooled CCD detectors for neutral wind measurement in the upper atmosphere. Earth Planets Space 55:271-275

Shiokawa K., Otsuka Y, Ogawa T, Kawamura S, Yamamoto M, Fukao S, Nakamura T, Tsuda T, Balan N, Igarashi K, Lu G, Saito A, Yumoto K (2003b) Thermospheric wind during a storm-time large-scale traveling ionospheric disturbance. J Geophys Res 108(A12):1423. doi:10.1029/2003JA010001

Shiokawa K, Otsuka Y, Ogawa T, Wilkinson P (2004) Time evolution of high-altitude plasma bubbles imaged at geomagnetic conjugate points. Ann Geophys 22:3137-3143

Shiokawa K, Lu G, Otsuka Y, Ogawa T, Yamamoto M, Nishitani N, Sato N (2007) Ground observation and AMIE-TIEGCM modeling of a storm-time traveling ionospheric disturbance. J Geophys Res 112:A05308. doi:10.1029/2006JA011772

Shiokawa K, Otsuka Y, Ogawa T (2009) Propagation characteristics of nighttime mesospheric and thermospheric waves observed by optical mesosphere thermosphere imagers at middle and low latitudes. Earth Planets Space 61:479-491

Sahai Y, Fagundes PR, Bittencourt JA (2000) Transequatorial F-region ionospheric plasma bubbles: Solar cycle effects. J Atmos Solar-Terr Phys 62:1377-1383

Sobral JHA, deCastilho VM, Abdu MA, Takahashi H, Paulino I, Gasparelo UAC, Arruda DCS, Mascarenhas M, Zamlutti CJ, Denardini CM, Koga D, de Medeiros AF, Buriti RA (2011) Midnight reversal of ionospheric plasma bubble eastward velocity to westward velocity during geomagnetically quiettime: Climatology and its model validation. J Atmos Solar-Terr Phys 73:1520-1528

Tinsley BA, Rohrbaugh RP, Hanson WB, Broadfoot AL (1997) Images of transequatorial $F$ region bubbles in 630- and 777-nm emissions compared with satellite measurements. J Geophys Res 102:2057-2077

Tsugawa T, Saito A, Otsuka Y (2004) A statistical study of large-scale traveling ionospheric disturbances using the GPS network in Japan. J Geophys Res 109:A06302. doi:10.1029/2003JA010302

Tsugawa T, Shiokawa K, Otsuka Y, Ogawa T, Saito A, Nishioka M (2006) Geomagnetic conjugate observations of large-scale traveling ionospheric disturbances using GPS networks in Japan and Australia. J Geophys Res 111:A02302. doi:10.1029/2005JA011300

Uma G, Liu JY, Chen SP, Sun YY, Brahmanandam PS, Lin CH (2012) A comparison of the equatorial spread $\mathrm{F}$ derived by the International Reference lonosphere and the S-4 index observed by FORMOSAT-3/COSMIC during the solar minimum period of 2007-2009. Earth Planets Space 64:6,467-471. doi:10.5047/eps.2011.10.014

Woodman RF, La Hoz C (1976) Radar observations of $F$ region equatorial irregularities. J Geophys Res 81:5447-5466

\section{Submit your manuscript to a SpringerOpen ${ }^{\circ}$ journal and benefit from:}

- Convenient online submission

- Rigorous peer review

- Immediate publication on acceptance

- Open access: articles freely available online

- High visibility within the field

- Retaining the copyright to your article

Submit your next manuscript at $\boldsymbol{\nabla}$ springeropen.com 